Tropical Journal of Pharmaceutical Research February 2011; 10 (1): 19-25

(C) Pharmacotherapy Group, Faculty of Pharmacy, University of Benin,

Benin City, 300001 Nigeria.

All rights reserved.

Research Article

Available online at http://www.tjpr.org

\title{
Prescribing Patterns and Inappropriate Use of Medications in Elderly Outpatients in a Tertiary Hospital in Nigeria
}

\author{
Uchenna IH Eze ${ }^{1 *}$ and Adebiyi O Olowu ${ }^{2}$ \\ ${ }^{1}$ Department of Clinical Pharmacy and Biopharmacy, ${ }^{2}$ Paediatrics Department, Obafemi Awolowo College of Health \\ Sciences, Olabisi Onabanjo University, PMB 2022, Sagamu, Nigeria.
}

\begin{abstract}
Purpose: To determine the prescribing patterns and occurrence of potentially inappropriate medications (PIM) among elderly outpatients visiting a tertiary hospital in Nigeria.

Methods: A retrospective study was carried out among elderly subjects (age $\geq 60$ years) who were issued prescriptions in the outpatients department of Olabisi Onabanjo University Teaching Hospital (OOUTH), Sagamu, Nigeria. Data were obtained on demographics, prescribing indicators and potentially inappropriate medications using Beer's criteria.

Results: Of the 1000 prescriptions consecutively selected, 546 (54.6\%) were for women and 454 were for men, giving a female to male ratio of 1:0.83. The mean age of the subjects was $68.9 \pm 7.3$ years. Analgesics (756, $75.6 \%)$ were the most commonly prescribed medicines. Prescription of antimalarials was low 127 (12.7\%). The total number of medications prescribed was 3979 while the mean number of medications per encounter was 3.9. The medications prescribed by generic name were 1945 (48.9 \%). Encounters with antibiotic and injection prescriptions were 203 (23\%) and $8(0.8 \%)$, respectively, while the proportion of medications prescribed that were on Nigeria's essential medicines list or formulary was $95.4 \%$. Four hundred and fifty six (45.6\%) prescriptions had one or more potentially inappropriate medicine. Medicines with high and low severity for potentially adverse events occurred in $82.7 \%$ and $17.3 \%$ of the cases, respectively.

Conclusion: Medication prescribing among the elderly is still suboptimal. Appropriate interventions are required from all stakeholders.
\end{abstract}

Keywords: Elderly, Medications, Drug utilization, Potentially inappropriate medications. 


\section{INTRODUCTION}

In spite of the widespread use of prescription drugs by the aged population, prescribing for the elderly may be less than optimal [1] and research has documented widespread inappropriate medication prescribing for the elderly [2]. Factors such as patient age, multiple diseases and disease severity, use of multiple medications, physicians' lack of training in geriatrics as well as changes in pharmacokinetics and pharmacodynamics in elderly patients often result in increase in the incidence of drug toxicity and adverse drug reactions (ADRs) [3]. The identification of the quantity and type of prescribing problems are fundamental first steps in trying to improve the quality of prescribing and medication safety. Both require that rational drug prescribing be promoted and potentially dangerous prescribing patterns be detected quickly [4] and discouraged. Much drugrelated morbidity in the elderly population may be avoidable as it is due to inappropriate prescribing [5].

Beers et al developed criteria for identifying potentially inappropriate medications $[6,7]$. Their recommendations focused on drugs that should be avoided or not given, excessive dosing and excessive duration of treatment. Using Beer's list, one-fourth of all elderly people living in a community were prescribed an inappropriate medication [8]. An updated Beers' list stated criteria defining medications that generally should be avoided in elderly patients, regardless of the setting [9].

Studies pertaining to prescription drugs have been carried out in Nigeria [10-13]; however, there is paucity of studies combining prescribing patterns and inappropriate prescribing in a special population such as the elderly. Hence, the main aim of this study was to determine the utilization of prescription drugs and occurrence of potentially inappropriate medications among elderly outpatients attending a tertiary hospital in Sagamu, Nigeria. Specific objectives include to describe the pattern of prescription medicines (therapeutic groups) issued to elderly patients; to evaluate prescribing practices using WHO core prescribing indicators; and to ascertain the extent of potentially inappropriate prescribing for elderly patients using explicit criteria.

\section{METHODS}

\section{Study design}

A retrospective study was carried out using prescriptions (encounters) issued to elderly patients, 60 years and above, attending the outpatient clinics of Olabisi Onabanjo University Teaching Hospital (OOUTH), Sagamu, western Nigeria. This hospital is a 218-bed facility which also serves as a referral centre

\section{Sample size and selection}

A total of 1000 prescriptions for patients $\geq 60$ years old emanating from different outpatient clinics of the hospital were consecutively selected. This large sample size, which exceeded the minimum of 100 suggested by WHO [14], was employed in order to enhance the reliability of the results since only one health facility was used in the study.

\section{Data collection}

A WHO prescriber indicator form [14] was used to collect and record demographic information obtained from the selected prescriptions. Other data collected include prescribing indicators such as the total number of medicines prescribed as generics and name of prescribed medicine according to therapeutic group. The extent of potentially inappropriate outpatient prescribing for these elderly patients was ascertained using Beer's updated criteria [9].

\section{Data analysis}

For easy sorting, the data obtained were entered into Microsoft Excel 2000 and Graph 
Pad software, version 2.05a (Graph Pad Software Inc, San Digeo, USA) was used for further analysis. $P<0.05$ was interpreted as significant. The mean and standard deviation of the categorical variables stated above were obtained. Test of significance was carried out using $z$ score and $p$ value of $\leq$ 0.05 was taken to be significant. Analysis for inappropriate prescribing was based on Beer's updated list of medications that generally should be avoided in elderly patients independent of diagnosis [9].

\section{Procedure for calculating prescribing indicators}

Average number of drugs per encounter was calculated by dividing the total number of drugs prescribed by the number of prescriptions surveyed. Percentage of drugs prescribed by generic name was determined by dividing the number of drugs prescribed by generic name by the total number of drugs, which was then multiplied by 100 . Percentage of encounters with an antibiotic and injection prescription was calculated by dividing the number of patient encounters during which an antibiotic or an injection was prescribed by the total number of encounters surveyed, which was then multiplied by 100 , respectively. Percentage of drugs prescribed from the essential drug list was determined by dividing the number of products prescribed from the essential drug list of the hospital by the total number of drugs prescribed, and then multiplied by 100 .

\section{RESULTS}

\section{Demographics}

The demographic characteristics of the patients are shown in Table 1. Out of 1000 prescriptions studied, 546 (54.6\%) belonged to women and the rest (454 or $45.4 \%$ ) to men, giving a female to male ratio of 1:0.83. The mean age was $68.9 \pm 7.3$ years.
Table 1: Demographic characteristics of the patients $(\mathrm{N}=1000)$

\begin{tabular}{ll}
\hline Characteristics & Frequency (\%) \\
\hline Age (years) & \\
$60-64$ & $375(37.5)$ \\
$65-69$ & $220(22.0)$ \\
$75-79$ & $201(20.1)$ \\
$75-84$ & $103(10.3)$ \\
$\geq 80$ & $101(10.1)$ \\
Sex & \\
Male & $546(54.6)$ \\
Female & $454(45.4)$ \\
\hline
\end{tabular}

\section{Prescribed medicines}

The distribution of the medicines prescribed into their therapeutic groups is shown in Table 2. Analgesics were the most prescribed medicines $(\mathrm{N}=756,75.6 \%)$ with acetylsalicylic acid (ASA) being the most prescribed analgesic (35.4\%). Vitamins and minerals $(\mathrm{N}=731,73.1 \%)$ ranked second while cardiovascular drugs such as antihypertensives (nifedipine, methyldopa, lisinopril, etc), antianginal drugs (glyceryl trinitrate and iso-sorbide dinitrate) and cardiac glycosides (digoxin) made up 504 $(50.4 \%)$ of the prescriptions.

Table 2: Therapeutic distribution of encountered medicines per prescription

\begin{tabular}{lcc}
\hline Therapeutic group & $\begin{array}{c}\text { Frequency } \\
\text { (N=1000) }\end{array}$ & \% \\
\hline Analgesics & 756 & 75.6 \\
Vitamins /Minerals & 731 & 73.1 \\
Cardiovascular drugs & 504 & 50.4 \\
Psychotherapeutic drugs & 326 & 32.6 \\
Diuretics & 316 & 31.6 \\
Antibiotics & 286 & 28.6 \\
Antidiabetics & 182 & 18.2 \\
Respiratory system drugs & 171 & 17.1 \\
Gastrointestinal drugs & 135 & 13.5 \\
Antimalarial drugs & 127 & 12.7 \\
Eye drops (for conjunctivitis & & \\
and glaucoma) & 78 & 7.8 \\
Anti allergic drugs & 66 & 6.6 \\
Others & 301 & 30.1 \\
\hline
\end{tabular}

Psychotherapeutic drugs occurred in 326 $(32.6 \%)$ of the prescriptions and the major groups encountered were hypnotics and 
sedatives (bromazepam, nitrazepam, etc) constituting $185 \quad(56.7 \%$ \%), tricyclic antidepressants (amitrptyline) 101 (30.9\%), anticonvulsants (carbamazepine) 34 (10.4\%) and antipsychotics (haloperidol and chlopromaxine) 6 (1.8\%). Diuretics occurred in $316(31.6 \%)$ of the prescriptions with amiloride + hydrochlorothiazide being the most prescribed with 129 (40.8\%). Thirty one different antibacterials were prescribed, with cotrimoxazole ( $\mathrm{N}=145,15.7 \%$ ) being the single most prescribed antibacterial.

More females received all therapeutic groups of drugs except for cardiovascular, antidiabetic and respiratory tract and antiallergy drugs. However, there was a significant difference between males and females in respect of vitamins and minerals $(z=-10.71, p=<0.001)$, antidiabetics $(z=$ 4.33, $p=0.0001)$ and psychotherapeutic agents $(z=-3.23, p=0.0268)$ respectively. Only marginal significant gender difference was obtained for respiratory agents $(z=1.93$, $p=0.0268$ ).

\section{WHO prescribing indicators}

The distribution of the number of medicines prescribed is shown in Figure 1.

\section{Average number of medicines per encounter}

The average number of medicines per prescription was 3.9; the range being 1 to 11 medicines.

\section{Percentage of medicines prescribed by generic name}

A total of $1945(48.9 \%)$ of the drugs were prescribed in their generic names with $58 \%$ of them having at least 1-2 medicines written in generics.
Percentage of encounters with an antibiotic prescribed

Two hundred and thirty (23\%) prescriptions had one or more antibiotics prescribed.

\section{Percentage of encounters with an injection prescribed}

A total of $8(0.8 \%)$ of the prescriptions had at least one injection prescribed along with other drugs.

\section{Percentage of drugs prescribed from the national essential drugs list}

Most of the medicines (95.4\%) were prescribed from the Nigerian Essential Drugs List.

\section{Extent of potentially inappropriate medicines}

Of the 1000 prescriptions studied, 456 (45.6 $\%$ ) had one or more potentially inappropriate medicines from Beers' list. This accounted for $601(15.1 \%)$ of all the medicines prescribed. The average age of those affected was 69.3 \pm 6.9 years, $269(58.9 \%)$ of whom were women. Of those in the 60 - 69 years age group, 285 (62.5\%) were mostly affected.

Three hundred and thirty five $(73.5 \%)$ of the potentially inappropriate prescriptions had a single drug on Beers' List. One hundred and twelve $(24.6 \%)$ of the prescriptions had two different medicines of concern (methyldopa and nifedipine) and $9(1.9 \%)$ had $3-4$ medicines from Beers' List occurring concurrently.

Table 3 shows the most commonly prescribed medicines in this study from Beers' list, by generic name and severity of potentially adverse events.

Medicines with high severity for potentially adverse events, including nifedipine, amitryptyline etc, occurred in $82.7 \%$ of the cases while medicines with low severity for 


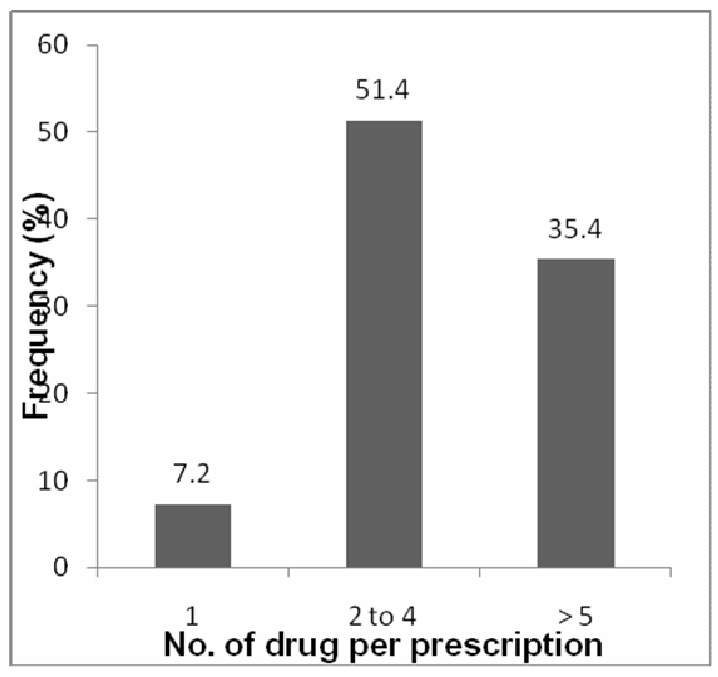

Figure 1: Frequency of single and multiple medicines in prescriptions

Table 3: Most commonly prescribed drugs in this study based on updated Beers list, by generic drug name and severity of potentially adverse events

\begin{tabular}{lll}
\hline $\begin{array}{l}\text { Generic name of } \\
\text { drug }\end{array}$ & $\begin{array}{l}\text { Frequency } \\
\text { (N=601) }\end{array}$ & (\%) \\
\hline High severity & & \\
Nifedipine & 143 & 23.79 \\
Amitryptyline & 101 & 16.81 \\
Methldopa & 96 & 15.97 \\
Chlopheniramine & 64 & 10.65 \\
Diazepam & 37 & 6.16 \\
Naproxen & 21 & 3.49 \\
Piroxicam & 19 & 3.16 \\
Amlodipine & 6 & 0.99 \\
Diphenhydramine (in & & \\
cough mixtures) & 4 & 0.67 \\
Chlopropamide & 2 & 0.33 \\
Nitrofurantoin & 1 & 0.17 \\
Promethazine & 1 & 0.17 \\
Bisacodyl & 1 & 0.17 \\
Low severity & & \\
Ferrous sulphate & 52 & 8.65 \\
Digoxin & 43 & 7.15 \\
Cimetidine & 5 & 0.83 \\
Dypyridamole & 4 & 0.67 \\
\hline
\end{tabular}

potential adverse events occurred in $17.3 \%$ of the cases. Of the 456 prescriptions with one or more drugs from Beers list, 143 (31.4 $\%$ ) had nifedipine occurring alone or in combination with other drugs such as amitryptyline and methyldopa. Nifedipine accounted for nearly a quarter $(23.8 \%)$ of the total medicines that were potentially inappropriate with amitryptyline coming a close second $(22.2 \%)$.

\section{DISCUSSION}

This study revealed the use of many therapeutic groups among the elderly. Analgesics were the most frequently prescribed, with ASA ranking as the highest of them. This finding is similar to those of other studies which also indicated that analgesics were the most prescribed medicines although these studies were based on palliative care [15-16].

The use of analgesics in the elderly is usually due to complaints of body pains by this special population. In addition to its analgesic effect, ASA was prescribed for its cardioprotective properties. Vitamins and minerals were the second most prescribed medicines. The high occurrence of vitamins and other health supplements in the prescriptions is not surprising as most people do not consume an optimal amount of all vitamins by diet alone. Pending strong evidence of effectiveness from randomized trials, it appears prudent for adults to take vitamin supplements. Physicians should make specific efforts to learn about their patients' use of vitamins to ensure that they take only the vitamins that they should [17].

Antihypertensives were highly prescribed too, indicating a high occurrence of hypertension in this population. The frequency of antimalarials in the prescriptions (3.2\%) was low. This is contrary to expectations considering the fact that the study location is endemic for malaria; on the other hand, these patients probably indulge in self-medication whenever they suffer malaria attack since 
antimalarials are available over the counter in retail pharmacy outlets.

Based on $\mathrm{WHO}$ prescribing indicators, some of the prescribing practices encountered in this study fell short of standard requirements. For instance, the number of medicines per prescription was found to be higher than the recommended range of 1.6 - 1.8. Such high values have been found in previous Nigerian medicines use studies [12,18]. This may result in problems such as patients taking more medicines than their body systems can cope with, non-adherence to treatment regimen and therapeutic failure, e.g., from drug-drug interaction.

Less than half of the medicines prescribed were generics. This finding is similar to those of previous studies [12,18] but falls short of WHO recommendation of $100 \%$. This implies that the prescribers are not complying with this recommendation although a majority of the drugs in Nigeria's essential drugs are listed in their generic names. Prescription of medicines in their brand names often result in increased cost to the patient which may in turn lead to non-adherence to the prescribed drugs.

It is worth noting that prescribing of antibiotics fell within the WHO recommended range of $20-26$, while prescribing of injections was lower than the recommended range of $\mathrm{WHO}$ ( $13.4-24.0 \%)$. A lower rate of injection prescribing (7.5\%) has also been reported by Akande and Ologe [12]. Both differ from the finding of Aghaji where prescribing of injectables was $26.9 \%$ [19] .

Of great importance is the occurrence of inappropriate prescribing among the elderly observed in this study. Almost half of the prescriptions met Beers' criteria for inappropriate prescribing in the elderly. Previous studies [3,20,21] also recorded potentially inappropriate medications though the level of occurrence is less than that found in our study. This and other studies [3,20-21], all point to one fact: inappropriate prescribing represent an important health problem for elderly patients and a major challenge for health practitioners. The reasons for inappropriate prescribing may be partly due to the relatively weak evidence-based guidelines for appropriate prescribing in elderly patients and existence of particulars justifying exceptions to the rules in individual patients [4].

Inappropriate medication use in patients 65 or older has been linked to many adverse drug reactions, poor physical functioning and excess healthcare use [22]. Interventions could target more appropriate drug selection by physicians when prescribing drugs such as short-acting nifedipine, methyldopa, amitryptyline, etc, to elderly patients as these were the most inappropriately prescribed medicines. Incidentally, amitryptyline was also found to be inappropriately prescribed in an earlier study, along with chlopropamide, propoxyphene and dypyridamol [21].

Interestingly, women and patients in their 'sixties' were the most at risk. This could be related to their being the modal gender and age, respectively, and therefore, interventions should be targeted to these groups.

\section{Limitations}

The results reported here are subject to some limitations. The study may not be totally generaliazable to all elderly since it was conducted using prescriptions of elderly persons attending outpatient clinics and did not include in-patients and other elderly people in the area.

\section{CONCLUSION}

Prescribing for the elderly was found to be suboptimal and there was occurrence of inappropriate prescribing. This calls for caution on the part of prescribers and pharmacists alike and also the need for awareness of tools that can be used by practitioners for detecting drug therapy problems. More studies are required on the 
pattern of inappropriate prescribing over a long period of time and on intervention programs to reduce potentially adverse health outcomes in elderly patients most at risk in the area where this study was undertaken.

\section{REFERENCES}

1. Monane $M$, Cataldi A. Safe prescribing: Interdisciplinary solutions. Geriatric Times 2000; $1: 1$

2. Agency for Healthcare Research and Quality. Up to one in five elderly prescribed potentially inappropriate medication. Press Release, December 11, 2001; .Rockville, MD, USA.

3. Drug prescribing in the elderly. 1995-2004. [cited 2004 Sept 8]. Available from Mayo Clinic, Rochester website: www.mayo.edu.

4. Curtis LH, Ostbye T, Sendersky V, Hutchison S, Dans $P E$, Wright $A$, Woosley $R L$, Schulam KA. Inappropriate prescribing for elderly Americans in a large outpatient population. Arch Intern Med . 2004; 164: 1621-1625

5. Lindley CM, Tully MP, Paramsothy $V$ and Tallis $R C$.Inappropriate medication is a major cause of adverse drug reactions in elderly patients. Age and Aging 1992; 21: 294-300

6. Beers $M H$, Ouslander JG, Rollinger I, Reuben DB, Brooks J, Beck JC. Explicit criteria for determining inappropriate medication use in nursing homes. Arch Intern Med 1991; 151(9): 1825-1832.

7. Beers $\mathrm{MH}$. Explicit criteria for determining potentially inappropriate medication use by the elderly. An update. Arch Intern Med 1997; 157(14): 1531-1536.

8. Wilcox SM, Himmelstein DU, Woolhandler $S$. Inappropriate drug prescribing for community dwelling elderly. JAMA 1999; 272: 292-296

9. Fick DM, Cooper JW, Wade WE, Waller JL, Macklean $I R$, Beer $M H$. Updating the Beers criteria for potentially inappropriate medication use in older adults. Arch Intern Med 2003; 163(22): 2716-2724
10. Adikwu MU. Prescription pattern in some Nigerian health centres: Implications for rational drug use. West. Afr. J.Pharm 1998; 12(2): 40-43

11.Chukwuani CM, Onifade $M$, Sumonu K. Survey of drug use practices and antibiotic prescribing pattern at a general hospital in Nigeria PWS 2002; 24(5): 188-195.

12. Yusuf $K B$, Balogun $O B$. Pattern of drug utilization among hypertensive in a Nigerian teaching hospital. Pharmacoepidemiol Drug Safety 2004; 14(1): 69-74.

13. Akande TM, Ologe MO. Prescription pattern at a secondary Health Care Facility in Illorin, Nigeria. Ann Afr Med 2007; 9(4): 186-189.

14. How to investigate drug use in health facilities selected drug use indicators. DAP Research series No. 7 WHO DAP 193.1

15. Drummond SH, Peterson GM, Galloway JG, Keefe $P A$. National survey of drug use in palliative care. Palliative Medicine 1996; 10(2): 119-124.

16. Koh $N Y$, Koo WH. Polypharmacy in palliative care: Can it be reduced? Singapore Med J 2002; 43(6): 279-283

17. Fletcher RH, Fairfield KM. Vitamins for Chronic Disease Prevention in Adults Clinical Applications. JAMA. 2002; 287:3127-3129

18. Enwere OO, Salako BL, Falade CO. Prescription and Cost Consideration at a Diabetic Clinic in Ibadan, Nigeria:A Report..Annals Ibadan Postgrad Med.2006; 4(2): 35-39.

19. Aghaji MN. Injection practices in Enugu.Nigeria. J. College Med 2002; 7: 118-120.

20. Zhan C, Sangl J, Bierman AS, Miller MR, Fredman B, Wickizer SW, Meyer GS . Potentially inappropriate medication use in the community dwelling elderly. Findings from the 1996 Medical Expenditure Panel Survey. JAMA 2001; 286(22): 2823-2829.

21.Raji MA, Ostir GV, Markides KS, Espino DV, Goodwin JS. Potentially inappropriate medication use by elderly Mexican Americans. Ann Pharmacother 2003; 37(9): 1197-1202

22. Goulding MR. Inappropriate medication prescribing for elderly ambulatory care patients. Arch Intern Med 2004;164(3):305-312 